7 Patel MX, Haddad PM, Chaudhry IB, McLoughlin S, Husain N, David AS. Psychiatrists' use, knowledge and attitudes to first- and second-generation antipsychotic longacting injections: comparisons over 5 years. J Psychopharmacol 2010; 24: 1473-82.

8 Gören JL, Meterko M, Williams S, Young GJ, Baker E, Chou CH, et al. Antipsychotic prescribing pathways, polypharmacy, and clozapine use in treatment of schizophrenia. Psychiatr Serv 2013; 64: 527-33.
9 Dixon LB, Dickerson F, Bellack AS, Bennett M, Dickinson D, Goldberg RW, et al. Schizophrenia Patient Outcomes Research Team (PORT). The 2009 schizophrenia PORT psychosocial treatment recommendations and summary statements. Schizophr Bull 2010; 36: 48-70.

10 Dweck CS, Leggett EL. A social-cognitive approach to motivation and personality. Psychol Rev 1998; 95: 256-73.

\title{
Psychiatric Disorder among the Yoruba by Alexander H. Leighton, T. Adeoye Lambo, Charles C. Hughes, Dorothea C. Leighton, Jane M. Murphy and David B. Macklin (Cornell University Press, 1963)
}

\section{Niran Okewole}

There are a number of reasons why one might revisit a book published 54 years ago. At the time of publication, Psychiatric Disorder among the Yoruba provided a strong rebuttal of many of the prevailing ideas regarding the 'African mind'. Ethnopsychiatry, the predominant theoretical framework of the colonial era, which governed the way the mind of 'the African' was perceived by the settler colonials, had held sway for the previous half century. Against the poorly grounded theorising of supposed experts such as Carothers, as well as others at different points along the spectrum of expertise, the Cornell-Aro project sought to provide empirical data regarding the mental health of an African community.

The methodological approach, which was a combination of psychiatric and sociological/anthropological investigation, was also novel at the time. Thitherto, there had been little or no cross-talk between psychiatrists and sociologists, which nevertheless did not prevent them from making sweeping generalisations. African communities were largely viewed as 'primitive' cultures and theorised as such.

One key strength of this work is the rigour with which the question of cultural distortion is approached. It bears remembering that this was mid-20th century, and the descriptive, phenomenological approach of Jaspers was engaged in mortal combat with the theory-driven postulates of psychoanalysis. In any case, anthropologists like Malinowski claimed that having investigated some 'primitive' cultures, they found no evidence for the Oedipus complex there. If a universal, atheoretical language of psychiatry was to gain ascendancy, signs and symptoms had to be the same across cultures. The collaborative effort - the objective could not have been achieved otherwise - between psychiatrists and sociologists, Yoruba and American, generated previously unavailable data which helped fuel a paradigm shift: the investigators found that the identification of symptoms of mental illness (with the exception of entities such as phobias and obsessive-compulsive disorder) among the Yoruba was considerably similar to European and American populations. Although there were some similar ideas about causation (drugs and medicines, heredity, contagion, physical and psychological trauma), the Yoruba gave prominence to other ideas (notably malignant influences, superhuman and human, violation of one's destiny, and fate). These ideas persist to this day, and have only been amplified by Christianity and Islam.

Besides the obvious debt to Emil Durkheim's concept of anomie, a current of thought prominent at the time of publication, against which the book can also be read, is Fanonism. While the work of Leighton et al was contemporaneous with the publications of Fanon, one benefit of reading it half a century later is that it is possible to see the lines of intersection. Leighton et al sought to investigate the concept of social integration/disintegration as an environmental risk factor for mental illness. Having found the same in the Stirling County study, the authors reported a higher prevalence of mental disorders in disintegrated Yoruba communities. Indeed, they suggested that the less integrated communities in the American and Yoruba studies had more in common with each other than their better integrated neighbouring communities. This fortuitously can be read into the Fanonist framework, if one views the impact of colonialism as disruptive of the colonised communities. Several studies since then have reported disparate prevalence, especially along the rural/urban dichotomy. A contemporary area of deficit however is the ploughing back of these data into psychosocial theory.

On the shelves today there is hardly any work to match the scope or address the questions raised over half a century ago by Leighton et al. Nor is there likely to be. Leighton et al, while seeking to entrench a methodology of objective phenomenological enquiry, were beneficiaries of a culture of close observation. This close clinical scrutiny is gradually being de-emphasised in the training of psychiatrists. At the same time, as biological psychiatry gains ascendancy, the chasm between psychiatry and sociology/anthropology may well be widening. Knowledge production as an interdisciplinary enterprise is left the poorer.

The authors acknowledged their limitations, some of which were limitations of the state of psychiatry itself. Nevertheless, they managed to produce a landmark volume which stands as a gentle rebuke in our time. 